\title{
Yields and Daily Consumption of Cigarettes in Japan in 1969-1996
}

\author{
Hajime Sato and Shunichi Araki
}

\begin{abstract}
Cigarette modification trends and the relationship between nicotine yields and consumption in Japan were examined over the 27 years between 1969-1996. Data on cigarette use were obtained from reports published by the government and tobacco manufacturers. Over the study period, there has been a coherent pattern of cigarette modification in Japan. The sales-weighted average yields have declined from $20.7 \mathrm{mg}$ tar and $1.64 \mathrm{mg}$ nicotine/cigarette in 1969 to $8.7 \mathrm{mg}$ tar and $0.72 \mathrm{mg}$ nicotine/cigarette in 1996. On the other hand, the average daily consumption per smoker has continuously increased over the same period. Average nicotine yields and daily cigarette consumption have significant negative correlations among both males and females. This relationship was observed even after controlling for the price changes of cigarettes over time. It is indicated that smokers have compensated for reduced nicotine yields by increasing daily consumption. This may have offset potential benefits of the continuous decline in tar and nicotine yields to smokers' health. J Epidemiol, 2000;10:7-15
\end{abstract}

tobacco smoking, cigarette yields, daily consumption, Japan

The health hazards of smoking have been known for decades, yet many countries have found it difficult to control smoking ${ }^{1,2)}$. Japan has had, and continues to have, one of the highest rates of smoking prevalence among the industrialized countries. In 1950, smoking prevalence among those over 19 years old was $81.8 \%$ among males and $13.4 \%$ among females. Since then, smoking among males has been on a continuous downward trend, falling to $59.8 \%$ in 1993 , while it has increased slightly among females, to $13.8 \%{ }^{3}$. On the other hand, Japan has increasing incidences of smoking-related diseases over the same period. In 1990, lung cancer, for example, became the second most frequent malignancy both among males and females; mortality rates from lung cancer were 44.3/100,000 among males and 15.4/100,000 among females. Then, in 1993, it became the most frequent cause of death due to malignancy for adult males in Japan (14,981 deaths from lung cancer in 1993) ${ }^{3,4}$.

Among the causal agents of smoking hazards, nicotine and tar have been known as hazardous since the 1950s, to which have been added through the years carbon monoxide, thio- cyanate and various other alkaloids ${ }^{5,6)}$. Together with other socio-psychological factors, nicotine, a potent psychoactive drug, plays a central role in smoking motivation and its maintenance ${ }^{7-9}$. At the same time, it is associated with various heart diseases ${ }^{6}$. On the other hand, tar, the particulate component of tobacco smoke, affects the sensory aspects of the habit and is believed to have the carcinogenic activity. A series of studies disclosed that tar has a dose-response relationship with lung cancer incidences ${ }^{10-12}$ ).

While a decrease in the numbers of smokers is quite important for the health of a whole population, the intake of these substances from tobacco products is also the important factor affecting the disease incidences among recalcitrant smokers. Therefore, since early reports published in the UK and the US, reduction of these substances has been argued by some as a possible measure to decrease the hazardous effects of smoking ${ }^{13,14}$. Since knowledge about the hazardous substances in cigarettes became widespread as a result of the efforts of health advocacy institutions and mass media, cigarette manufacturers have persuaded health conscious smokers

Received February 9, 1999 ; accepted May 19, 1999.

Department of Public Health and Occupational Medicine, Graduate School of Medicine, The University of Tokyo.

Address for correspondence: Hajime Sato, Department of Public Health and Occupational Medicine, Graduate School of Medicine, The University of Tokyo, Hongo 7-3-1, Bunkyo-ku, Tokyo 113-0033 Japan. 
to cling to their habits by switching to low yield ( $5 \mathrm{mg}$ tar) products. As a consequence, the yields of various tobacco products, such as tar, nicotine and carbon monoxide, have been gradually declining in several countries ${ }^{15}$.

This study first examines the modification of cigarette products in Japan, specifically the trend toward reduction of their tar and nicotine yields, and the changes in smokers' daily consumption between 1969 and 1996. The relationship between nicotine yields and consumption is analyzed from these longitudinal cross-sectional data. Although many believe that low yield cigarettes might be safer than the higher ones ${ }^{16)}$, the clinical meaning of machine-measured yields remains controversial. Various methods of compensation for nicotine reduction, individual differences in smoking patterns, and socio-psychological factors affecting smokers' behaviors can affect the actual physical intake of many substances during smoking. The paper discusses the possible implications of cigarette yield changes and addresses the important research topics for many countries.

\section{MATERIALS AND METHODS}

Data were collected from the Japan Public Monopoly Corporation (JPMC), the public tobacco monopoly until its privatization in 1985, now known as Japan Tobacco Incorporated (JT) and the only tobacco manufacturer in Japan, archives specifically with regard to the cigarette yields of tar and nicotine (TN) and the numbers of cigarettes consumed by smokers. Since 1968, TN yields have been measured using the US Federal Trade Commission (FTC) method, first by the JPMC and its affiliated institutions ${ }^{17}$, and since 1986 by the Tobacco Institute of Japan: TN are measured by the smoking machines, which have the designated specifications of the puff length (1 second per minute), puff volume $(35 \mathrm{ml})$ and smoked length (to $3 \mathrm{~mm}$ from the filter overwrap) ${ }^{18}$ ). These yields have been publicized voluntarily every year since $1969^{19)}$. In 1989, part of the Tobacco Enterprise Law was amended and the disclosure of the TN yields of cigarettes became mandated by the law. Apart from those disclosure, the JPMC and JT (JPMC/JT) have conducted marketing surveys on smoking prevalence and on the daily cigarette consumption by smokers (the adults who smoke cigarettes either habitually or occasionally). They have been annual nationwide surveys targeting those over the age of 19 with the sample sizes of $16,000^{18}$. In addition to the industry records on TN yields, this study used the results of these surveys as published in the government report ${ }^{3}$.

To examine time trends, the sales-weighted yields of TN and the average numbers of cigarettes consumed were plotted over time. To explore the relationship between the nicotine yields of cigarettes and their consumption, Pearson's correlation coefficients were calculated between them. Then, linear regression analysis was conducted with the average daily consumption as a dependent variable and the sales-weighted average nicotine yield and the real cigarette price as independent variables, for both male and female smokers. Real cigarette prices were calculated as the average cigarette prices deflated by the wage indices. Their ratios to the 1995 price were put into models. Both the average cigarette prices and the wage indices were obtained from the government reports ${ }^{20,21)}$.

\section{RESULTS}

The sales-weighted average yields of nicotine and tar have gradually decreased since 1969 (Fig. 1). The average tar yields were $20.7 \mathrm{mg}$ in 1969 and $8.7 \mathrm{mg}$ in 1996, while the average nicotine yields were $1.64 \mathrm{mg}$ in 1969 and $0.72 \mathrm{mg}$ in 1996 . Although the nicotine yields increased slightly during a few years after the market liberalization of 1985, the downward trend in nicotine yields resumed in 1989. Overall reductions were $58.0 \%$ in tar yields and $56.1 \%$ in nicotine yields during the 27 years between 1969 and 1996.

On the other hand, the average daily consumption in Japan has continuously increased over the study period (Fig. 2). In 1968, male smokers smoked 19.7 pieces a day on average, while female smokers consumed 13.2 cigarettes per day. In 1996, the former smoked 24.3, and the latter 17.4 cigarettes per day. The nicotine yields and the average numbers of cigarettes consumed have significant negative correlations both for male smokers and for female smokers: Pearson's correlation coefficients were -0.90 for males $(\mathrm{p}<0.001)$ and -0.85 for females $(\mathrm{p}<0.001)$. Linear regression models also show that the decrease in nicotine yields tends to increase the consumption levels for both sexes, controlling for real cigarette prices (Table. 1).

\section{DISCUSSION}

\section{Changes in Nicotine Yields and its Intake}

The sales-weighted average yields of tar and nicotine in Japanese cigarettes have decreasing trends over the 27 years between 1969 and 1996. These changes can be attributed both to the changes in consumer preference and to the marketing force, two aspects which must be in accord for a product to gain popularity ${ }^{22)}$. The JPMC/JT have revealed the TN yields of its marketed cigarettes since 1969. A series of surveys showed that Japanese smokers tended to change their brands for lower TN yields or decrease their consumption in response to the accumulating evidence of the hazards of smoking ${ }^{3,23)}$. In accordance, cigarette companies have marketed a variety of products, responding to the changing preferences of smokers. Reductions in delivery of TN have been technically accomplished by changing filter designs and tobacco blending, and by smoke dilution. Filter-tipped cigarettes were marketed first in 1957 and soon gained popularity in Japan: their market 


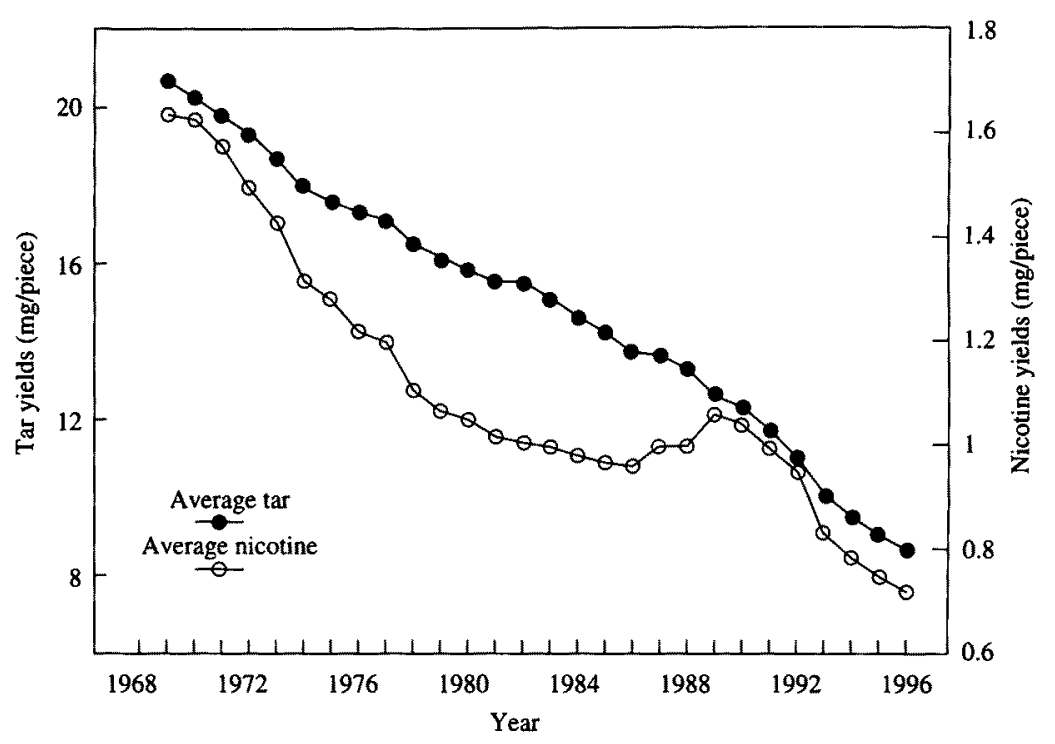

Figure 1. Average Tar and Nicotine Yields of Cigarettes 1969-1996.

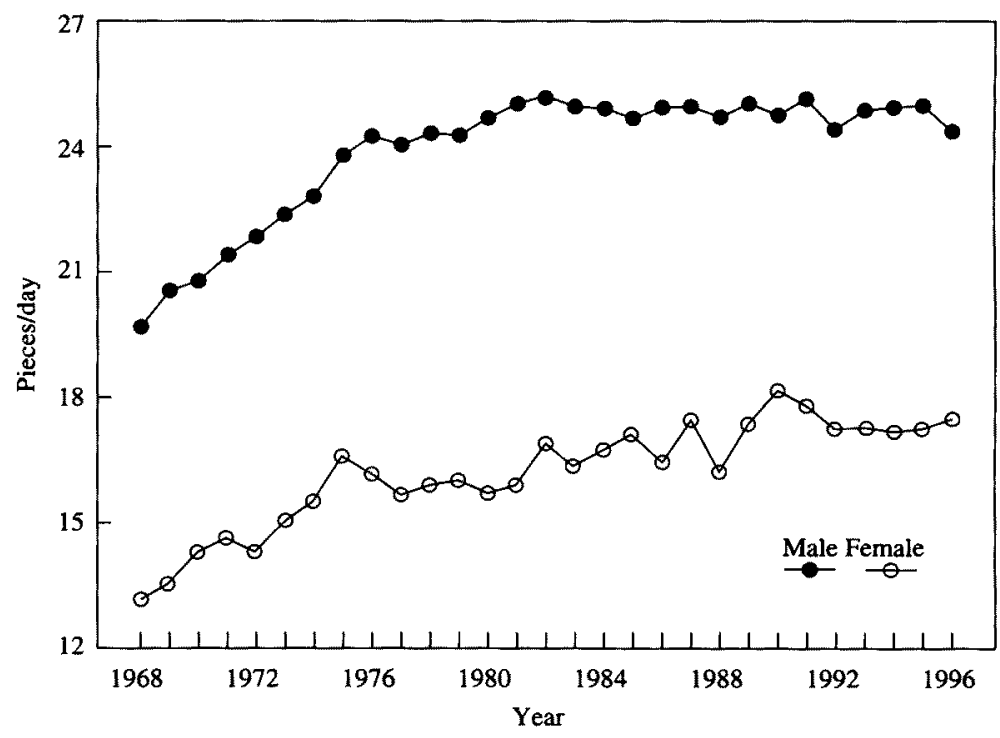

Figure 2. Average Daily Consumption 1968-1996.

share was $90 \%$ in 1970 , and more than $98 \%$ after $1980^{24,25)}$. Also, the Ministry of Finance recommended the lowering of TN contents in 1972, based on the 1970 WHO resolution ${ }^{26)}$.

Looking more closely at the trends of nicotine yields over time, one notices that liberalization of Japan's cigarette market in 1985 caused a pause in the downward trend. As the sales of American-type cigarettes, which tended to have higher nicotine yields than the conventional Japanese products, grew, the sales-weighted average nicotine yields also increased. At the same time, the JPMC/JT maintained certain levels of nicotine yields to keep their cigarette sales ${ }^{27,28)}$. Some even argue that manufacturers artificially increased the nicotine content to gain or maintain the market shares of their products ${ }^{29}$. As a consequence, the nicotine yields remained fairly stable within a nar- 
Table 1. Results of multiple regression analysis of average daily consumption of cigarettes versus average nicotine yields and cigarette prices.

\begin{tabular}{lccc}
\hline & \multicolumn{3}{c}{ Regression coefficients } \\
\cline { 2 - 4 } Variables & Estimate & Standard error & Significance \\
\hline (males) & & & \\
Average nicotine yield ${ }^{\mathrm{a})}$ & -2.84 & 0.66 & $\mathrm{p}<0.001$ \\
Real cigarette price ${ }^{\mathrm{b}}$ & -1.38 & 0.39 & $\mathrm{p}<0.01$ \\
(females) $_{\text {Average nicotine yield }}^{\mathrm{a})}$ & -2.49 & 0.77 & \\
Real cigarette price $^{\mathrm{b}}$ & -0.93 & 0.45 & $\mathrm{p}<0.01$ \\
\hline
\end{tabular}

a) Sales-weighted average nicotine yield ( $\mathrm{mg} /$ piece).

b) Average cigarette price deflated by wage index (ratio to the 1995 price).

row range between 0.95 and $1.05 \mathrm{mg} / \mathrm{piece}$ in the $1980 \mathrm{~s}$. When the ultra-low cigarettes ( $1 \mathrm{mg}$ tar and $0.1 \mathrm{mg}$ nicotine) were introduced in the late 1980 s, their market share rapidly increased, amounting to four to five percent by $1993^{30)}$. We can infer that the ultra-low cigarettes contributed to the reversal of the upward trend of nicotine yields which began in 1990 .

Both in the UK and in the US, the sales-weighted average nicotine yields have been declining since the 1950s. Nicotine yields in 1968 were $2.08 \mathrm{mg}$ in the UK and $1.35 \mathrm{mg}$ in the US, while they were $1.27 \mathrm{mg}$ and $0.94 \mathrm{mg}$ respectively in $1987^{31-33)}$. They declined further to $0.85 \mathrm{mg}$ in the UK and $0.90 \mathrm{mg}$ in the US in $1995^{34,35)}$. In these countries, the steepest declines took place with the introduction of filter tips in the late 1950 s. Almost simultaneously, tobacco manufacturers introduced reconstituted tobacco products and then adopted porous papers for cigarettes. Expanded tobacco was introduced in the late 1960 s, as was ventilation around 1970. These technological changes in cigarette design further contributed to the reduction of nicotine yields ${ }^{36}$. During the 1980s, the sales-weighted average nicotine yield leveled off: Between 1981 and 1989, the average nicotine delivery of US cigarettes remained stable at $0.9 \mathrm{mg}$ per cigarettes and the average nicotine yields of UK cigarettes at somewhat above that level ${ }^{37,38)}$. Then, ultra-low products with new air vent designs, whose ventilation percentage varies inversely with nicotine yield, were introduced ${ }^{39}$. The decline in nicotine yields and the changes in cigarette design reported in these countries appear comparable to those observed in Japan.

It is reported that each smoker maintains his/her nicotine intake within narrow limits of his/her own, although the range varies greatly across individuals ${ }^{40,41}$. Smokers are likely to adopt various compensation methods for the decreased nicotine yields. When switching to cigarettes with lower nicotine content, they may increase their nicotine intake by increasing their consumption ${ }^{42,43)}$, changing their smoking patterns, such as puff volumes, duration and intervals ${ }^{44-47}$, and by blocking air vents ${ }^{48)}$. Consequently, the physiological intake of nicotine is, at most, weakly correlated with the nominal yields $40,49-51$, and is more reflective of the consumption levels ${ }^{43,52,53)}$. The extent of overall compensation remains controversial, from reports of incomplete compensation ${ }^{54-57}$ to those which found more complete compensation ${ }^{58-60)}$. As was their original intent, yields simply indicate the relative yields of the various brands according to a convention of analytical standards ${ }^{62)}$. The clinical implications of the yield reduction observed in this study are not necessarily obvious.

Although compensation by an increase in consumption was not always observed ${ }^{50,55,58,62)}$, such negative results could be explained by the taste changes involved in experimental brand switching, as well as by the adoption of alternative compensation methods. Smokers might not usually get accustomed to new (switched) brands in a short term and therefore do not increase their consumption. Furthermore, experiments cannot be the same as actual circumstances: While all smokers are forced to change their brands in experiments, under natural conditions, the switch to lower yield cigarettes might be maintained only by those who managed to compensate fully. Therefore, observation of cigarette brand changes and their effects on consumption over longer periods would provide more realistic pictures of brand switching, since smokers would be allowed sufficient time to accommodate to differences in sensory properties and to reestablish their smoking methods.

The present study shows that average nicotine yields and daily consumption have a significant negative correlation. Price changes can affect smoking prevalence and levels of consumption ${ }^{63)}$. However, the results of regression analysis indicate that the negative correlation between nicotine yields and consumption holds true, controlling for cigarette prices. Smokers have inferably increased consumption to compensate for the decreased nicotine yields of their cigarettes. While Garfinkel ${ }^{64)}$ reported no significant increase in consumption despite decreasing nicotine levels in the UK, his study analyzed only 13 years between 1959 and 1972 . Moreover, the 
introduction and popularity of low and ultra-low yield cigarettes took place thereafter.

The possibility has been suggested that smokers who maintain their nicotine intake at relatively lower levels are likely to choose lower yield products ${ }^{57}$. It has also been reported that while switching from high or middle TN products to low yield products does not affect the physical nicotine intake, switching to ultra-low brands produces a significant decrease ${ }^{65,66)}$. This suggests that declining average nicotine yields and the recent popularity of ultra-low cigarettes could result in a decrease in nicotine intake among smokers, but this remains to be confirmed ${ }^{67,68)}$.

\section{Changes in Tar Yields and its Intake}

This study found that the sales-weighted average tar yields have also continuously decreased in Japan. Over the same period, the UK and US markets observed a similar decline in the average tar yields of their cigarettes. In 1968, average tar yields were $23.9 \mathrm{mg}$ in the UK and $21.6 \mathrm{mg}$ in the US, and only 12.1 $\mathrm{mg}$ and $11.0 \mathrm{mg}$ respectively in $1994{ }^{32,33,35,69)}$. These reductions can be attributed to the changes in consumer preference and in cigarette design, as was discussed above in the section on changes in nicotine yields. In Japan, in response to the emerging nonsmokers' rights movement in the late 1970s, the JPMC planned to decrease tar yields, while maintaining certain levels of nicotine ${ }^{28)}$. Accordingly, the JPMC, and later the JT, marketed many products with lower tar yields. In the 1990s, a decade later, most of the newly marketed products have tar yields less than $6 \mathrm{mg}$, and their market share has rapidly increased: from $0.6 \%$ in 1984 to $26.4 \%$ in $1993^{7,71)}$

It should be noted that the decrease in nominal tar yields does not necessarily mean the reduction of physical tar intake by smokers. The tar yield, as is the case with nicotine, does not closely coincide with the level of its physical metabolites, which presumably represent its actual intake into the human body. When smokers regulate their nicotine intakes (which themselves vary greatly), their tar intakes could be affected by the tar-to-nicotine ratios of their cigarettes. Here the ratios are not always constant: When smokers change their smoking patterns, such as puff intervals, the ratios of tar intake to nicotine intake change, even when their yields remain constant ${ }^{56,72)}$. Various estimation methods for tar intake have been developed, based on the relationship among the intake of different substances: They employ the yields or intakes of nicotine, tar to nicotine ratios and/or carbon monoxide as the adjustment factors ${ }^{50,55,56,73)}$. However, information on most of these variables, including the sales-weighted averages of the ratios of tar yields to nicotine yields, is not readily available in Japan, nor in many other countries.

According to a cross-sectional study on the US cigarette market, high tar cigarettes tend to have higher tar to nicotine ratios ${ }^{74}$. This suggests that increased market share of low tar products can result in lower average tar to nicotine ratios, and therefore, smokers are likely to intake less tar even when compensating for reduced nicotine yields. However, this is just a speculation, which is yet to be confirmed.

\section{Considerations of Possible Confounders}

It is important to consider the effects of confounders in interpreting the results, although they are not controllable due to limitations of data availability and the design of this study. In the first place, the sales-weighted TN yields are not tabulated by age and gender, while the average daily consumption is not tabulated by age. The sales-weighted average yields are the averages of the yields of each cigarette brand weighted by its market share. Since each market share is based on the wholesale volume, it cannot be sorted by age or gender. In Japan, smoking prevalence among males has remained considerably higher (about four to seven fold) than the prevalence among females ${ }^{3)}$. Average daily consumption among the former is also greater than among the latter. Further, male smokers are more likely to prefer high tar/nicotine brands ${ }^{75)}$. Considering these facts, the actual average TN yields would be higher for males and lower for females than the averages for both genders used in this study.

No data are available in regard to the TN levels for different age groups. It can be inferred that older smokers are more likely to choose high tar/nicotine brands like those which they established their smoking habits in their youths, although recently they have tended to switch their brands to lower TN products ${ }^{70}$. On the other hand, a series of new products with middle to low TN yields has been introduced to the market, targeting younger generations ${ }^{75)}$. These new products may affect the relationship between the age groups and their brand preferences, but their full consequences remain unknown. Similarly, consumption data tabulated by age are not available. Sporadic surveys in recent years have disclosed that the average daily consumption of cigarettes is highest in the forties both among males and females ${ }^{76}$. The average consumption data, as well as the sales-weighted cigarette yield data, reflect therefore those of this generation more than those of the others: smokers under forty years old or over fifty are likely to smoke less than the consumption data average for them all. Because of this difference in consumption across age groups, a change in the population structure of smokers could result in a modification of the overall consumption average for all age groups.

Other confounding variables may include the levels of various marketing activities, such as product development and promotion. Market segmentation, for example, has become more subtle to accompany enhanced product differentiation, just as market competition became more fierce after liberalization 77 . Also, changing norms that become more accepting toward smoking by females could affect smoking in that segment of the population ${ }^{78)}$. 
Finally, since the present study is not based on follow-up of certain cohorts, but rather on the series of cross-sectional survey data, it may reflect a changing population of smokers. This implies that the observed changes may not be behavioral changes among the same smokers, but could result from changes in who smokes. It has been pointed out that more heavily dependent smokers are less likely to quit than are lighter dependent smokers ${ }^{79}$. However, the possibility cannot be ruled out that the observed decline in the average TN yields occurred as those smoking high yields quit and those smoking lower yields started their smoking. In the same vein, consumption increases could be a result of the fact that heavier smokers joined, while lighter smokers left, the smoking population. Under these circumstances, the correlation observed between nicotine yields and daily consumption is an outcome of the changing smoking population, namely the decrease in smokers who consume more cigarettes with lower yields, rather than any real switching of brands among the same population. The results of this study should be confirmed by a longitudinal cohort study, which would examine how specific cohorts of smokers change their behaviors.

\section{Changing Cigarettes and Smoking Control}

Changing cigarettes and smoking patterns can reportedly affect the incidences of lung cancer and chronic obstructive pulmonary diseases ${ }^{80,811}$. The issue is not only tar and nicotine: The intake of other substances, such as carbon monoxide, thiocyanate and many additives, should be explored fully in relation to changing product designs, consumption patterns and smoking methods ${ }^{74,82,837}$. The intake of carbon monoxide is associated with the levels of consumption ${ }^{50,74,84}$. Development of low-yield cigarettes has necessitated an enrichment of the flavor "bouquet" in the smoke either by tobacco selection or by addition of natural or synthetic flavor compounds ${ }^{85,86)}$. The impact of these changes has not been studied in many countries.

Accumulating evidence suggests that the present set of labels do not represent the physical intake of hazardous substances. Many smokers, however, do not understand the true meaning of the yields, and tend to think that lower yield cigarettes are safer than others ${ }^{16)}$. In 1996, the Massachusetts Department of Public Health developed a testing method which better simulates the smoking behavior of the average smoker under normal conditions, and which revealed nicotine yield levels to be about twice as high as those found by the FTC ${ }^{87}$. The FTC itself is now considering the revision of its test method for tar and nicotine yields ${ }^{88)}$. Labels that more accurately reflect actual human intake of hazardous substances would help people make informed choices on smoking and could be a potent tool to decrease the health risks of smoking ${ }^{89.90)}$.

Furthermore, in several countries regulation of the contents of tobacco products has been proposed as a measure to decrease their harmful effects. Limits of cigarette yields, such as upper limits for tar and nicotine, have already been specified in a number of countries ${ }^{14)}$. It cannot be emphasized enough, however, that simply decreasing nicotine yields is not effective: Any policy must take smokers' compensation into account. At the same time, it must be remembered that many smokers will not choose products under certain levels of nicotine yield ${ }^{91}$. As an alternative, several researchers have proposed that the composition of the substances in cigarettes should be arranged to decrease the delivery of hazardous substances while maintaining smokers' satisfaction by supplying certain levels of nicotine ${ }^{29,92,93)}$.

\section{CONCLUSIONS}

This study considered important aspects of smoking changes in cigarettes, and their consumption in Japan. Average yields of tar and nicotine in Japanese cigarettes have decreasing trends over the 27 years between 1969 and 1996. The study also found a continuous increase in the average daily consumption of cigarettes among smokers. Its significant negative correlation with nicotine yields indicates that smokers have increased their consumption to compensate for the diminishing nicotine yields of their cigarettes. The potential benefits to them of the reduction of cigarette yields may have been offset by the increased daily consumption, as well as by the other possible changes in their smoking patterns.

The implications of the trends in tar and nicotine delivery documented here for the risk of developing smoking-related diseases is to be explored in the future. A study on hazardous effects on the health of smokers caused by changes in cigarettes, as well as a study of changing smoking patterns, would be important for the world health community as it develops effective strategies to diminish the health hazards of smoking.

\section{ACKNOWLEDGMENTS}

The authors greatly appreciate the valuable comments and suggestions from Dr. Gregory Connolly and Ms. Denise Lymperis, Massachusetts Tobacco Control Program, Department of Public Health, the Commonwealth of Massachusetts.

\section{REFERENCES}

1. American Cancer Society. World smoking and health 14. American Cancer Society, Washington DC, 1990: 1-21.

2. Kluger R. Ashes to ashes. America's hundred-year cigarette war, the public health, and unabashed triumph of Phillip Morris. Alfred and Knopf, New York, 1996.

3. Ministry of Health and Welfare (MHW). Smoking and health, Second edition. Health Promotion and Fitness 
Foundation, Tokyo, 1993 (in Japanese).

4. Health and Welfare Statistics Association. Health and welfare statistics 1996. Health and Welfare Statistics Association, Tokyo, 1996 (in Japanese).

5. International Agency for Research on Cancer. Tobacco Smoking: Monograph 38. IARC, Lyon, 1986.

6. Department of Health and Human Services (DHHS). The health consequences of smoking: Nicotine addiction. A report of the Surgeon General, 1988. US Government Printing Office, Washington DC, 1988: Chapter 6.

7. Darby TD, McNamee JE, Rossum JM. Cigarette smoking pharmacokinetics and its relationship to smoking behavior. Clinical Pharmacokinetics, 1984; 9: 435-449.

8. Benowitz NL. Pharmacologic aspects of cigarette smoking and nicotine addiction. New Engl J Med, 1988; 319 : 1318-1330.

9. Benowitz NL. Pharmacokinetic considerations in understanding nicotine dependence: The biology of nicotine dependence. Chiba Foundation Symposium, 1990; 152: 186-209.

10. Kaufman DW, Palmer JR, Rosenberg L, et al.. Tar content of cigarettes in relation to lung cancer. Am J Epidemiology, 1989; 129: 703-711.

11. Stellman SD, Garfinkel L. Lung cancer risk is proportional to cigarette tar yield: Evidence from a prospective study. Preventive Medicine, 1989; 18: 518-525.

12. Zang EA, Wynder EL. Cumulative tar exposure: A new index for estimating lung cancer risk among cigarette smokers. Cancer, 1992; 70: 69-76.

13. Royal College of Physicians. Smoking or Health. Third report of the Royal College of Physicians. Pitman Medical, London, 1977.

14. Roemer R. Legislative action to combat the world tobacco epidemic, Second edition. World Health Organization, Geneva, 1993: Chapter 5.

15. Davis $R$. Current trends in cigarette advertising and marketing. N Engl J Med, 1987; 316: 725-732.

16. Cohen JB. Smokers' knowledge and understanding of advertised tar numbers: Health policy implications. Am J Public Health, 1996; 86: 18-24.

17. Japan Public Monopoly Corporation (JPMC). History of Japan Tobacco Monopoly. Volume 4. JPMC, Tokyo, 1978: 796-805 (in Japanese).

18. Anonymous. Measurement of tar and nicotine yields. Tabako Sangyo, Septermber 15, 1997: 8.

19. JPMC. History of Japan Tobacco Monopoly. Volume 5. JPMC, Tokyo, 1978: 693-711 (in Japanese).

20. Bureau of Statistics, Office of the Prime Minister. Japan statistical yearbook. Japan Statistical Association, Tokyo, 1998 (in Japanese).

21. Bureau of Statistics, Management and Coordination Agency. Annual report on consumer price indices. Japan
Statistical Association, Tokyo, 1998 (in Japanese).

22. Kotler P. Marketing management: Analysis, planning, implementation, and control. Prentice Hall, Englewood Cliffs, 1991.

23. JPMC. Market change and future product development. Tobacco Nippon, 1978; 50: 33-41 (in Japanese).

24. JPMC. History of Japan Tobacco Monopoly. Volume 5. JPMC, Tokyo, 1978: 515-516 (in Japanese).

25. JPMC. History of Japan Tobacco Monopoly. Volume 6. JPMC, Tokyo, 1990: 89-93 (in Japanese).

26. Advisory Council on Tobacco Business, Ministry of Finance. On the tobacco business in relation to the issue of smoking and health. Ministry of Finance, Tokyo, 1971 (in Japanese).

27. Izumi Y. Tobacco story. Finance, 1974; 10: 47-50 (in Japanese).

28. Imai T, Uchida J, Ebinuma Y, et al.. Marketing activity. Tobacco Nippon, 1978; 52: 21-36 (in Japanese).

29. Benowitz NL, Henningfield JE. Establishing a nicotine threshold for addiction: The implications for tobacco regulation. N Engl J Med, 1994; 331: 123-125.

30. Anonymous. Recent popularity of ultra-low cigarettes. Tabako Sangyo, April 20, 1994: 12.

31. Garfinkel L. Changes in number of cigarettes smoked compared to changes in tar and nicotine content over a 13-year period. In; Gori GB and Bock EG, eds. A safe cigarette? Banbury report 3. Cold Spring Harbor Laboratory, Cold Spring Harbor, 1980: 19-28.

32. DHHS. Reducing the health consequences of smoking: 25 years of progress. A report of the Surgeon General, 1989. US Government Printing Office, Washington DC, 1989: Chapter 5.

33. Wald N, Nicolaides-Bouman A. UK smoking statistics, Second edition. Oxford University Press, Oxford, 1991.

34. Federal Trade Commission (FTC). Tar, nicotine, and carbon monoxide of the smoke of 1206 varieties of domestic cigarettes for the year 1994-1997. The FTC Public Reference Branch, Washington DC, 1998.

35. Scientific Committee on Tobacco and Health. Report of the scientific committee on tobacco and health. The Stationery Office, London, 1998: Annex L.

36. DHHS. Reducing the health consequences of smoking: 25 years of progress. A report of the Surgeon General, 1989. US Government Printing Office, Washington DC, 1989: 87-88.

37. Fiore MC. Trends in cigarette smoking in the United States: The epidemiology of tobacco use. The Medical Clinics of North America, 1992; 76: 289-303.

38. Waller RE, Froggatt P. Product modification. Brit Med Bulletin, 1996; 52: 193-205.

39. Kozlowski LT. Filter ventilation levels in selected US cigarettes. MMWR, 1997; 46: 1043-1047. 
40. Benowitz NL, Jacob P. Nicotine and carbon monoxide intake from high- and low-yield cigarettes. Clin Pharmacol Ther, 1984; 36: 265-270.

41. Kozlowski LT, Herman CP. The interaction of psychosocial and biological determinants of tobacco use: More on the boundary model. J Appl Soc Psychol, 1984; 14: 244-256.

42. Stepney R. Consumption of cigarettes of reduced tar and nicotine delivery. Brit J Addiction, 1980; 75: 81-88.

43. Benowitz NL, Jacob P. Daily intake of nicotine during cigarette smoking. Clin Pharmacol Ther, 1984; 35: 499504.

44. Herning RI, Jones RT, Benowitz NL, Mines AH. How a cigarette is smoked determines blood nicotine levels. Clin Pharmacol Ther, 1983; 33: 84-90.

45. Moody PM. Human smoking patterns and smoke deliveries. The International Journal of the Addictions, 1984; 19: 431-439.

46. Bridges RB, Combs JG. Puffing typography as a determinant of smoke exposure. Pharmacology Biochemistry and Behavior, 1990; 37: 29-39.

47. Benowitz NL, Jacob P, Denaro C, et al.. Stable isotope studies of nicotine kinetics and bioavailability. Clin Pharmacol Ther, 1991; 49: 270-277.

48. Henningfield JE, Griffiths RR. Effects of ventilated cigarette holders on cigarette smoking by humans. Psychopharmacology, 1980; 68: 115-119.

49. Russell MAH, Jarvis M, Iyer R, et al.. Relation of nicotine yield of cigarettes to blood nicotine concentration in smokers. BMJ, 1980; 3: 972-976.

50. Gori GB, Lynch CJ. Analytical cigarette yields as predictors of smoke bioavailability. Regulatory Toxicology and Pharmacology, 1985; 5: 314-326.

51. Coultas DB, Stidley CA, Samet JM. Cigarette yields of tar and nicotine and markers of exposure to tobacco smoke. Am Rev Respir Dis, 1993; 148: 435-440.

52. Rickert WS, Robinson JC. Estimating the hazards of less hazardous cigarettes II: Study of cigarette yields of nicotine, carbon monoxide, and hydrogen cyanide in relation to levels of cotinine, carboxyhemoglobin, and thiocyanate in smokers. J Toxicol Environ Health, 1981; 7: 391-403.

53. Andersson G, Vala EK. Curvall M. The influence of cigarette consumption and smoking machine yields of tar and nicitone on the nicotine uptake and oral mucosal lesions in smokers. J Oral Pathol Med, 1997; 26: 117-123.

54. Ashton H, Stepney R, Thompson JW. Self-titration by cigarette smokers. BMJ, 1979; 2: 357-360.

55. Russell MAH, Sutton SR, Iyer R, et al.. Long-term switching to low-tar low-nicotine cigarettes. Brit J Addiction, 1982; 77: 145-158.

56. Russell MAH, Jarvis MJ, Feyerabend C, et al.. Reduction of tar, nicotine and carbon monoxide intake in low tar smokers. J Epidemiol Community Health, 1986; 40: 8085.

57. Byrd GD, Robinson JH, Caldwell WS, et al.. Comparison of measured and FTC-predicted nicotine uptake in smokers. Psychopharmacology, 1995; 122: 95103.

58. Robinson JC, Young JC, Richert WS, et al.. A comparative study of the amount of smoke absorbed from low yield ( less hazardous') cigarettes Part 2: Invasive measures. Brit J Addiction, 1983; 78: 79-87.

59. Benowitz NL, Hall SM, Herning PJ, et al.. Smokers of low-yield cigarettes do not consume less nicotine. N Engl J Med, 1983; 309: 139-142.

60. Guyatt AR, Kirkham AJT, Mariner DC, et al.. Long-term effects of switching to cigarettes with lower tar and nicotine yields. Psychopharmacology, 1989; 99: 80-86.

61. FTC. Cigarettes: Testing for tar and nicotine content statements of consideration. Federal Regulation, 1967; 32: 11178.

62. Battig K, Buzzi R, Nil R. Smoke yield of cigarettes and puffing behavior in men and women. Psychopharmacology, 1982; 76: 139-148.

63. Lewit EM, Coate T. The potential for using excise taxes to reduce smoking. J Health Economics, 1982; 1: 121145.

64. Garfinkel L. Changes in the cigarettes consumption of smokers in relation to changes in tar/nicotine content of cigarettes smoked. Am J Public Health, 1979; 69: 12741276.

65. Russell MAH, Wilson C, Patel US, et al.. Plasma nicotine levels after smoking cigarettes with high, medium and low nicotine yields. BMJ, 1975; 2: 414-416.

66. Benowitz NL, Jacob P, Yu L, et al.. Reduced tar, nicotine, and carbon monoxide exposure while smoking ultralow- but not low-yield cigarettes. JAMA, 1986; 256: 241-246.

67. Boren JJ, Stitzer ML, Henningfield JE. Preference among research cigarettes with varying nicotine yields. Pharmacology, Biochemistry and Behavior, 1990; 36: 191-193.

68. Maron DJ, Fortmann SP. Nicotine yield and measures of cigarette smoke exposure in a large population: Are lower-yield cigarettes safer? Am J Public Health, 1987; 77: 546-549.

69. Jarvis MJ, Russell MAH. Tar and nicotine yields of UK cigarettes 1972 - 1983: Sales weighted estimates from non-industry sources. Brit J Addiction, 1985; 80: 429434.

70. Anonymous. Decline of tar and nicotine yields. Tabako Sangyo, November 15, 1995: 14.

71. Anonymous. Cigarette market in 1996. Tabako Sangyo, January 15, 1997: 10-11. 
72. Kozlowski LT. Tar and nicotine delivery of cigarettes: What a difference a puff makes. JAMA, 1981; 245: 158159.

73. Woodward M, Tunstall-Pedoe H. Do smokers of lower tar cigarettes consume lower amounts of smoke components? Results from the Scottish Heart Health Study. Brit J Addiction, 1992; 87: 921-928.

74. Rickert WS, Robinson JC, Young JC, et al.. A comparison of the yields of tar, nicotine, and carbon monoxide of 36 brands of Canadian cigarettes tested under three conditions. Preventive Medicine, 1983; 12: 682-694.

75. JPMC. History of Japan Tobacco Monopoly. Volume 6. JPMC, Tokyo, 1990: 289-339.

76. Ministry of Health and Welfare. National Nutritional Survey of Japan, 1996. MHW, Tokyo, 1996 (in Japanese).

77. JPMC. History of Japan Tobacco Monopoly. Volume 6. JPMC, Tokyo, 1990: 274-288 (in Japanese).

78. Tabako Sogo Kenkyu Center (TASK). Sociological history of smoking: TASK research report 258-88. TASK, Tokyo, 1988 (in Japanese).

79. Hall SM, Herning RI, Jones RT, et al.. Blood cotinine levels as indicators of smoking treatment outcome. Clin Pharmacol Ther, 1984; 35: 810-814.

80. Stellman SD, Muscat JE, Hoffmann D, et al.. Impact of filter cigarette smoking on lung cancer histology. Preventive Medicine, 1997; 26: 451-456.

81. Wise RA. Changing smoking patterns and mortality from chronic obstructive pulmonary disease. Preventive Medicine, 1997; 26: 418-421.

82. Jaffe JH, Kanzler M, Friedman L, et al.. Carbon monoxide and thiocyanate levels in low tar/nicotine smokers. Addictive Bahaviors, 1981; 6: 337-343.
83. DHHS. The health consequences of smoking: The changing cigarettes. A report of the Surgeon General, 1981. US Government Printing Office, Washington DC, 1981.

84. Benowitz NL, Jacob P, Kozlowski LT, et al.. Influence of smoking fewer cigarettes on exposure to tar, nicotine, and carbon monoxide. N Engl J Med, 1986; 315: 1310-1313.

85. Anonymous. Smoking and health. Mainichi Shimbun, September 10, $1995: 14$.

86. DHHS. Reducing the health consequences of smoking: 25 years of progress. A report of the Surgeon General, 1989. US Government Printing Office, Washington DC, 1989: Chapter 8.

87. Massachusetts Department of Public Health. 1997 cigarette nicotine disclosure report: As required by Massachusetts General Laws Chapter 307B, CMR 660.000. Massachusetts Department of Public Health, Boston, 1998.

88. FTC. FTC's cigarette test method. The FTC Public Reference Branch, Washington DC, 1997.

89. Henningfield JE, Kozlowski LT, Benowitz NL. A proposal to develop meaningful labeling for cigarettes. JAMA, 1994; 272: 312-314.

90. Djordjevic MV, Hoffmann D, Hoffmann I. Nicotine regulates smoking patterns. Preventive Medicine, 1997; 26: 435-440.

91. Kozlowski LT. Evidence for limits on the acceptability of lowest-tar cigarettes. Am J Public Health, 1989; 79: 198199.

92. Russell MAH. Low-tar medium-nicotine cigarettes: A new approach to safer smoking. BMJ, 1976; 1: 14301433.

93. Kozlowski LT. Less hazardous smoking and the pursuit of satisfaction. Am J Public Health, 1987; 77: 539-541. 